\title{
Assessment of Spinal Cord Injured Patients' Adherence toward Clean Intermittent Self-Catheterization in Baghdad City
}

\author{
MOHAMMED A HUSSEIN ${ }^{1}$, WIDADK MOHAMMED ${ }^{2}$ \\ ${ }^{1}$ PhD Student, University of Baghdad -College of Nursing -Adult Nursing Department \\ ${ }^{2}$ Prof Dr. University of Baghdad -College of Nursing - Adult Nursing Department \\ Correspondence to Mohammed Abdul-Zahra Hussein: E-mail: alkenany.mohammed@yahoo.com
}

\begin{abstract}
Background: Patients with spinal cord injuries should adhere to the practice of self-intermittent catheterization, in order to reduce their urinary tract problems such as bladder stones or urinary tract infection and others.

Aim: To evaluate the spinal cord injured patients' adherence toward clean intermittent self-catheterization.

Methodology: A descriptive analytic study design was carried out to assess the spinal cord injured patients' adherence toward clean intermittent self-catheterization in Baghdad city. A non-probability (purposive) sample of (26) spinal cord injured patients with paraplegia. The study instrument was composed of two parts which: Sociodemographic characteristic and the patients' compliance with clean intermittent catheterization measured by Intermittent Catheterization Adherence Scale (ICAS).

Results: The majority of the samples (73\%) were (18-32) years old, (58\%) were single, (42\%) were primary graduate, and $(50)$ of those in median level of economic status. The results demonstrated a strong adherence of the patients to the self-intermittent catheterization.

Conclusion: The study indicated that the participants have a high adhere to the application of the clean intermittent catheterization.

Keywords: Assessment; Spinal Cord Injury; Adherence; Clean Intermittent Self-Catheterization.
\end{abstract}

\section{INTRODUCTION}

Spinal cord injuries result in many complications in most parts of the human body, which leads to a change in the lifestyle of the injured person ${ }^{1}$. Clinically, previous studies have observed a significant increase in spinal cord injuries, affecting more than 2 million people worldwide, and there are as near as more than 125,000 new cases of spinal cord injuries every year ${ }^{2}$. The Neurogenic bladder is one of the problems that accompany injuries of the central or peripheral nervous system as well as it is considered one of the most difficult problems facing the injured person, approximately more than $75 \%$ of patients who suffer from spinal cord injuries have the neurogenic bladder within one year of the injury every year.(1). Neurogenic bladder problems develop greatly in patients, so they must be managed and monitored well in order to avoid the occurrence of problems that cannot be treated in the future $^{3-5}$. Clean Intermittent catheterization is considered one of the best safe and effective ways to treat a neurogenic bladder, as it provides complete emptying of urine from the bladder, which leads to increased selfconfidence in affected people and improvement of body image as well as an increase in the quality of life $^{16}$. The clean intermittent catheterization procedure is performed by the individual himself or by one of his relatives, usually 4-6 times daily. A clean intermittent catheterization is also the ideal way to manage a neurogenic bladder by reducing urinary tract infection and other complications , $^{6,8-8-10}$. A person's hand skill is an essential requirement when performing clean intermittent catheterization ${ }^{8,9}$. Moreover, due to the cost of a clean intermittent catheterization the patient may need to reuse it after washing and cleaning it ${ }^{8}$. Some studies have demonstrated that the CIC coated with water (a polymer coating that reduces friction and inflammation) may reduce urinary tract infection when compared to uncoated catheters $6,10,11$.

\section{METHODOLOGY}

A descriptive analytic study design was carried out to assess the spinal cord injured patients' adherence toward clean intermittent self-catheterization in Baghdad city. A non-probability (purposive) sample of (26) spinal cord injured patients with paraplegia who were attending the Ibn Al-Kuff Hospital in Baghdad City for medical treatment and rehabilitation. The study instrument was composed of two parts which: Part 1. Socio-demographic characteristic was included; age, social status, level of education, occupational, and economic status. Part 2. The patients' compliance with clean intermittent catheterization measured by Intermittent Catheterization Adherence Scale $(\text { ICAS })^{12}$. Were adopted to assess the spinal cord injured patients adherence toward clean intermittent catheterization, It is a validated tool consisting of eight questions. The answers to the first seven questions were: Yes $=1$, No $=0$, while the answer to Question 8 was rated on a 5 -point Likert scale: 0 never, 0.25 sometimes, 0.5 often, 0.75 regularly, and 1 always, leading to a maximum possible score of 8 . The individual's score is experimentally categorized into three periods: Strong Adherence $=0$. Average Adherence $=1-2$. Low commitment $=3-8$. Data were collected through the use of questionnaire format designed and interview techniques. Data were analyzed through the application of descriptive and the inferential data analysis approach by using SPSS version 20 .

\section{RESULTS}

The demographic characteristic. Table 1 indicated that the majority of the samples (73\%) were (18-32) years old, $(58 \%)$ were single, $(42 \%)$ were primary graduate, $(27 \%)$ of those were middle school graduated $(23 \%)$ were secondary graduate , $(31 \%)$ were does not work and $(31 \%)$ were employee, and (50) of those in median level of economic 
status. The participants compliance with clean intermittent catheterization, table 2 where the results showed strong adherence in all items of the scale except for the seventh item, where the result was within the average adherence.
No statistical significant differences between the patients' compliance with clean intermittent catheterization and their demographic characteristics table

Table 1: Distribution of spinal cord injured patients by demographic characteristic $(n=26)$.

\begin{tabular}{|c|c|c|c|}
\hline Demographic variable & & $\mathbf{F}$ & $\%$ \\
\hline \multirow{5}{*}{ Age } & $18-22$ & 8 & 31.0 \\
\hline & $23-27$ & 5 & 19.0 \\
\hline & $28-32$ & 6 & 23.0 \\
\hline & $33-37$ & 4 & 15.0 \\
\hline & $38-42$ & 3 & 12.0 \\
\hline \multirow{2}{*}{ Social status } & Single & 15 & 58.0 \\
\hline & Marred & 11 & 42.0 \\
\hline \multirow{5}{*}{ Level of Education } & Not read or write & 1 & 4.0 \\
\hline & Primary graduate & 11 & 42.0 \\
\hline & Middle school graduated & 7 & 27.0 \\
\hline & Secondary graduate & 6 & 23.0 \\
\hline & Institute graduate & 1 & 4.0 \\
\hline \multirow{4}{*}{ Occupation } & Student & 4 & 15.0 \\
\hline & Employee & 8 & 31.0 \\
\hline & Free business & 6 & 23.0 \\
\hline & Does not work & 8 & 31.0 \\
\hline \multirow{3}{*}{ Economic Status } & Low income & 8 & 31.0 \\
\hline & Median Income & 13 & 50.0 \\
\hline & Good income & 5 & 19.0 \\
\hline
\end{tabular}

Table 2: Evaluation of Patients adherence regarding Clean Intermittent Catheterization

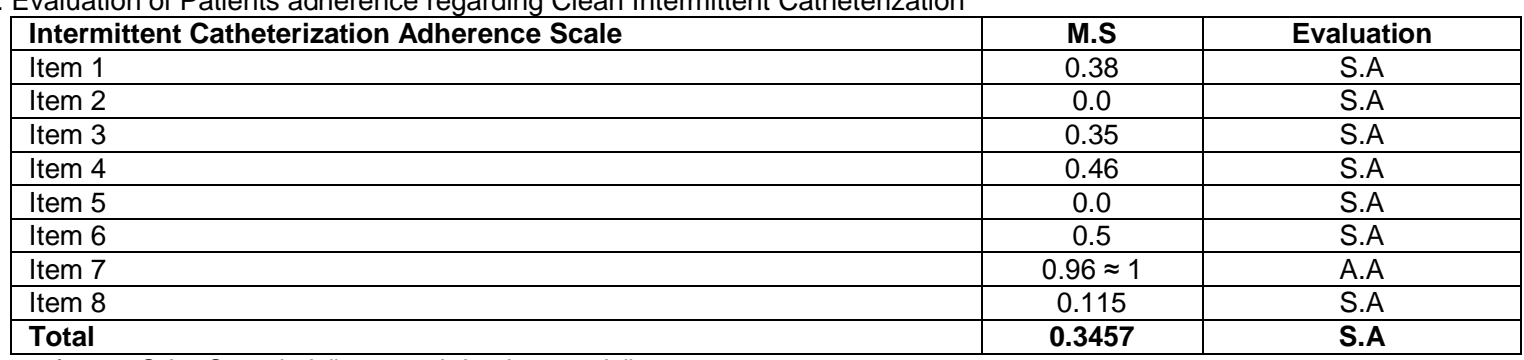

M.S = Mean of score, $\mathrm{S} . \mathrm{A}=$ Strongly Adherence, $\mathrm{A} . \mathrm{A}=$ Average Adherence.

Table 3: Association between patients' adherence toward clean intermittent self-catheterization and their socio demographic characteristic

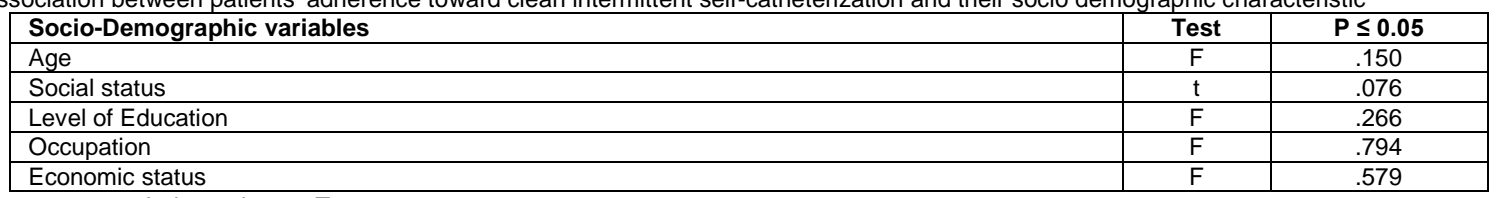

\section{DISCUSSION}

Socio-Demographic Characteristics of the Study Sample indicated that the majority of them $(73 \%)$ were $(18-32)$ years old , (27\%) were (33-42) years old, (58\%) were single $(42 \%)$ were married.Forty two percent graduated from primary school, (27\%) of those were middle school graduated (23\%) were secondary graduate, (31\%) were does not work, and (31\%) were employee, $(23 \%)$ were free business, and (50\%) of those in median level of economic status. Huang C. et al, (2019) ${ }^{13}$ they are established a study development of an assistant system of clean intermittent catheterization for neurogenic bladder dysfunction patients, and found the mean of age participants (39.25). Moreover, Afsar $S$ et al $(2013)^{14}$ reported that most of participants $(55.9 \%)$ of sample with primary graduate. Table 2 shows the participants 'compliance with clean intermittent catheterization, where the results showed strong adherence in all items of the scale except for the seventh item, where the result was within the average adherence. These results supported by Sang Rim L. et al, $(2018)^{15}$ they found that the median duration was twenty two days, compliance rate was $87.6 \%$ (198 of the 226). 28 patients were non-compliance and 16 of 28 did not performed clean intermittent catheterization at all.No statistical significant differences between the patients' compliance with clean intermittent catheterization and their demographic characteristics. These results agree with study done by Afsar $S$. et al $(2013)^{14}$ found that no any Factors affecting compliance with $\mathrm{CIC}$ at follow-up such as age, gender, educational level, and level of injury

\section{CONCLUSIONS}

The current study found a very high level of patients' compliance with the practice of clean intermittent 
catheterization. The study also recommended the necessity of intensifying educational programs on intermittent catheterization for nurses in order to teach them to patients suffering from neurogenic bladder.

Acknowledgements: This research was funded by Authors. Moreover, we would like to thank the all patients' participants in this study.

\section{REFERENCES}

1. Redshaw JD, Lenherr SM, Elliott SP, et al. Protocol for a randomized clinical trial investigating early sacral nerve stimulation as an adjunct to standard neurogenic bladder management following acute spinal cord injury. BMC Urol 2018; 18: 72. DOI:10.1186/s12894-018-0383-y.

2. Liu Q, Wu C, Huang S, et al. Decreased hyperpolarizationactivated cyclic nucleotide-gated channels are involved in bladder dysfunction associated with spinal cord injury. Int $\mathrm{J}$ Mol Med 2018; 41:2609-2618. DOI: 10.3892/ijmm.2018.3489.

3. Adriaansen JJ, van Asbeck FW, Tepper M,et al. Bladderemptying methods, neurogeniclower urinary tract dysfunction and impacton quality of life in people with long-termspinal cord injury. J Spinal Cord Med 2017;40: 43-53. DOI: 10.1179/2045772315Y.0000000056.

4. Hagen EM,Rekand T. Management ofbladder dysfunction and satisfaction of lifeafter spinal cord injury in Norway. $J$ SpinalCord Med 2014; 37: 310-316. DOI: 10.1179/2045772313Y.0000000171.

5. Jensen MP, Truitt AR, Schomer KG, et al.Frequency and age effects of secondaryhealth conditions in individuals with spinalcord injury: a scoping review. Spinal Cord2013; 51: 882-892. DOI: 10.1038/sc.2013.112.

6. Kreydin E, Welk B, Chung D, et al. Surveillance and management of urologic complications after spinal cord injury. World J Urol. 2018;36(10):1545-1553. doi:10.1007/s00345018-2345-0.

7. Groen J, Pannek J, Castro Diaz D, et al. Summary of European Association of Urology (EAU) guidelines on neuro- urology. Eur Urol. 2016;69(2):324-333. doi:10.1016/j.eururo.2015.07.071.

8. Bladder management following spinal cord injury. Spinal cord injury rehabilitation 2014. https://scireproject.com/evidence/rehabilitationevidence/bladder-management/.

9. Adult urethral catheterisation for acute care settings. http://www1.health.nsw.gov.au/pds/ ActivePDSDocuments/GL2015_016.

10. Kennelly $M$, Thiruchelvam N, Averbeck MA, et al. Adult neurogenic lower urinary tract dysfunction and intermittent catheterisation in a community setting: Risk factors model for urinary tract infections. Adv Urol. 2019;2019:2757862. doi:10.1155/2019/2757862

11. Hooton TM, Bradley SF, Cardenas DD, et al. Diagnosis, prevention, and treatment of catheter-associated urinary tract infection in adults: 2009 International Clinical Practice Guidelines from the Infectious Diseases Society of America. Clin Infect Dis. 2010;50(5):625-663. doi:10.1086/650482.

12. Guinet-Lacoste A, Charlanes A, Chesnel C. et al: Intermittent Catheterization Adherence Scale (ICAS): A new tool for the evaluation of patient adherence with cleans intermittent selfcatheterization, Neurourology and Urodynamics. wileyonlinelibrary.com/journal/nau, 2018; pp 1-5.

13. Huang $\mathrm{C}$. Wang J. Chen J. et al: development of an assistant system of clean intermittent catheterization for neurogenic bladder dysfunction patients, Journal/applsci, Appl. Sci. 2019, 9, 1433; doi: 10.3390/app9071433, pp. 1-11.

14. Afsar S. Yemisci O. Cosar S. et al: Compliance with clean intermittent catheterization in spinal cord injury patients: a long-term follow-up study, Spinal Cord (2013) 51, 645-649.

15. Sang Rim L. In Sook L. Seung-June, O. et al: Adherence to the Clean Intermittent Catheterization Following a Customized Intensive Education Program for Patients with Emptying Failure, J Korean Acad Community Health Nurs, Vol. 29 No. 4, 467-475, December 2018.

16. Silva DRA, Mazzo A, Jorge BM, Souza Júnior VD, Fumincelli L, Almeida RGS. Intermittent urinary catheterization: the impact of training on a low-fidelity simulator on the selfconfidence of patients and caregivers. RehabilNurs 2017:42:97-103. 